\title{
IMPLICATIONS OF THEORY AND RESEARCH ON STRATEGIC LEADERSHIP: A CRITICAL REVIEW
}

\section{ABSTRACT}

Strategic Leadership: Theory and Research on Executives, Top Management Teams, and Boards by Finkelstein, Hambrick and Canella Jr. (2009) is one of the most important references in strategy studies. This work is a critical review of this book and attempts to answer why organizations do what they do or play the way they play. In this paper, we review all eleven chapters that make up the book. We then suggest the implications of this theory on strategy and organizations. We also consider how this book affects the development of the field of study. The book offers considerable foundations for executives and serves as a reference for researchers who wish to understand the phenomenon related to strategic leadership, considering the CEO, Board and Top Management Team. The major contribution of this paper is that it summarizes the theory and concepts of the book in a few pages and identifies the main characteristics, antecedents and consequences of leadership in organizations.

Keywords: Strategic Leadership; CEO; Board; Top Management Team.

Carlos Roberto Banzato ${ }^{1}$ Julio Cesar Volpp Sierra ${ }^{2}$

\footnotetext{
${ }^{1}$ Doutorando em Administração pela Universidade Nove de Julho - UNINOVE. Brasil. E-mail: banzato00@hotmail.com

${ }^{2}$ Doutorando em Administração pela Universidade Nove de Julho - UNINOVE. Brasil. E-mail: volpp1979@gmail.com
} 


\section{INTRODUCTION}

Why do organizations do what they do or play the way they play? We need a deep understanding the people at the top of the structure - their experiences, skills, values, social connections, aspirations and other human characteristics to answer this simple question. The actions of a small group of key people at the top of an organization may affect organizational outcomes.

Seeking to answer this question, we have conducted a critical review of Strategic Leadership: Theory and Research on Executives, Top Management Teams, and Boards by Sidney Finkelstein, Donald C. Hambrick and Albert A. Canella Jr. The scope of strategic leadership includes executives as Chief Executive Officers (CEO), Top Management Teams (TMT) and the Board of Directors. The book covers topics related to CEOs, such as their values, personality, demographics, succession and compensation. Regarding TMTs, the book addresses their composition, processes and dynamics. Concerning board members, it discusses their behavior and profile.

The book review focuses on executives, top management teams and boards members in terms of their individual differences, behaviors and experiences, as well as how these affect organization outcome. What are the influences of executive turnover, succession, composition and compensation? How can the board structure influence executive behaviors and results for the organization?

The book offers scholars and executives a broad overview of how top management teams can influence organizational outcomes and help them take action in favor of the organization and their careers.

Regarding the authors, we mention Sidney Finkelstein as an authority on organizational leadership and strategy, listed among the 25 "gurus" in leadership (World's Top 25 Leadership Gurus). Donald C. Hambrick is a researcher in Management and the author of several books on strategy formulation, executive psychology, top management composition and processes and corporate governance teams. Albert A. Canella Jr. focuses on research on executives, corporate governance, competitive dynamics and entrepreneurship.

The book has eleven chapters that will be reviewed in next section.

\section{CRITICAL BOOK REVIEW}

\subsection{The study of top executives}

A small group of people at the top of organizations can dramatically affect the outcomes of companies. We will see in the following sections that people's actions are reflections of their circumstances. Human factors such as personality, past experiences, values and social connections, substantially affect the outcomes of an organization.

A firm's performance is directly linked to strategic choices, and these choices are made by people who act based on their own circumstances and motivations. Organizations become reflections of their top executives. John Child (1972) stated that strategic choices are exercised by those who have power within an organization at a given time. This power may be shared by board members, executives, investors and union leaders.

\subsection{Do top executives matter?}

Before discussing the relationship between top executives and organizational outcomes, it is necessary to understand what top executives actually do in an organization in terms of their roles, responsibilities, activities, arenas of action etc. To understand such actions, we can use the elements of various theories, such as the Fayol's segregation of activities (planning, organization, coordination, command and control) (Fayol, 1949), or Mintzberg's three categories of managerial roles (interpersonal, informational and decisional) (Mintzberg, 1973). These theories identify the top executives involved in internal and external activities, strategy formulation, implementation and creation of contexts, dealing with substantive issues in addition to symbolic and conceptual ones. They also include a wide range of possibilities to exercise their roles in their organizations.

In this context, some scholars argue that top executives are very important to organizational outcomes, while other argue the opposite, i.e., their irrelevance. In this discussion, there is a third viewpoint that seeks to bridge this gap, the idea of discretion or managerial discretion. This concept is used to identify the varying relevance of the role of top executives in profit organizations, according to the range of possibilities for their actions.

A number of variables from the environment, the organization and the individuals themselves affect this discretion. This series of variables can compose a multitude of combinations according to the intensity of each variable. Hambrick and Abrahamson (1995), for example, present a range of indicators for managerial discretion in seventy different industries. In addition to the industry, factors such as regulation, culture and tradition, sociological and economic elements are among the environmental variables that interfere with the managerial discretion of top executives. The stronger these elements are, the weaker the discretion tends to be.

Organizational variables such as size, age, organizational culture and capital intensity tend to limit the actions of CEOs, leading them to adopt a more inertial and reactive position. More recent research by Finkelstein and Peteraf (2007) has sought to highlight the role of the individual in seeking to overcome the 
limitations and restrictions of this discretion. Using research of agency theory and transaction costs, the authors discussed how top executives promulgate the environments, the nature of management skills and the interaction between restraint and alternatives.

Individual characteristics, such as aspirations, beliefs, tolerance of ambiguity, cognitive complexity, control, perceived power and political acumen can interfere with an executive's discretion in terms of action. These arenas require further empirical study and are becoming critical to the study of the individual capabilities of top executives.

All of these elements combined (managerial discretion) may influence, among other things, the CEO's succession, the successor's profile, tenure, and the size and configuration of the top management team. Discretion also affects strategic conformity to industry, strategic persistence and organizational outcomes as a moderating force between executive characteristics and organizational outcomes. High or low discretion may have adverse effects. However, much remains to be investigated with regard to executives' discretion.

\subsection{How individual differences affect executive action}

Executives act in a complex and ambiguous world. Strategic decisions represent an important part of an executive's workload, preferences and personality. According to the Carnegie School, which studies the theory of decisions, complex choices are determined more by behavioral factors than by factors calculated from an optimal situation.

Hambrick and Mason (1984) defined a model that explains the human limits in strategic decisions and how executives differ in their strategic choices. For a situation that requires a strategic decision, an executive makes decisions based on psychological factors such as values, cognitive style and personality. Other factors include age, formal education and professional background. The model proposed by the authors discusses the filtering process in decisionmaking considering that, the "filter" of the executive is composed of a limited field of view of the situation, a selective perception of the situation followed by an interpretation based on cognitive baggage and educational background. Executives build their reality in this filtering process and decide on their strategic choices, and will therefore be responsible for the organizational outcomes.

According to the authors, executives have different values and act accordingly. Personal and social values are involved. Personal ones are those to which the individual aspires (e.g., prestige, family safety, health and knowledge). Social values are related to what the individual finds and desires in others or in society (e.g., honesty, courage and world peace). A country's culture influences the values of executives, organizations and the values of their professionals. Executives whose values are aligned with those of the organization play their roles better. Hambrick and Brandon (1988) identified six dimensions that define the values of an executive: collectivism, rationality, innovation, duty, materialism and strength. The actions or strategic choices of executives are related to their values.

The values of executives will affect their field of vision, selectivity and interpretation of information. The cognitive content of an executive is what he knows, assumes and believes. This content is the result of personal and professional experiences that can arise from real events such as economic hardship, the bankruptcy of a business or a dishonest act of a customer or supplier. Familiarity with management tools and concepts of finance, marketing and product may also be at play. Cognitive content can be formed by another person's knowledge, consisting of simple facts, information and perceptions that affect the field of vision, perception and interpretation of information as well as choices.

Cognitive structure is how cognitive content is arranged, connected or placed in the executive's mind. Cognitive executive structure is a highly personalized interpretation of reality, not necessarily in line with objective conditions. Cognitive executive structure will affect the executive's field of vision, perception and interpretation of information and choices. We refer to cognitive style as how a person's mind works and how this person absorbs and processes information. An executive's cognitive style affects his field of vision, the perception and interpretation of information and choices.

Another aspect to consider, according to the authors, is the executive's personality, which can be defined as an ingrained disposition. The personality profile can define the types of executives who, for example, are more willing to take risks, are at their best in a competitive organizational environment, striving to win in the market rather than an environment that needs to maximize profits while maintaining market share. Other aspects of the executive's personality are related to risk tolerance, tolerance to ambiguity and the need to achieve goals. Another aspect that influences the performance of an organization and sometimes can even influence the value of its shares is the charisma of the first executive. Scholars have found evidence that the charisma of the executive generates a positive effect on the organization's performance even in adverse conditions. The executive's personality and charisma will affect his field of vision, perception and interpretation of information and choices.

Another executive personality may be called control of the situation (locus of control) with internal or external orientation (Rotter, 1966). Internal orientation occurs when the executive believes that the events in his life are under his control. External orientation occurs when the executive believes the events of his life are beyond his control and are the result of fate or luck. Studies confirm that executives in control of the situation with internal orientation are 
associated with high-performance organizations. These organizations are more innovative and better adapted to a dynamic environment than companies led by executives with external orientation. The locus of executive control will affect his field of vision, perception and interpretation of information and be reflected in his choices.

Another feature of an executive personality, according to the book, is self-esteem, control of the situation and emotional stability. Narcissism can be defined as the high degree that an individual has of his self-image and his concern over strengthening it continually. A narcissist executive is positively associated with dynamism and strategic grandeur as well as volatile and extreme organizational outcomes. Another aspect of personality is exaggerated selfconfidence. Psychological characteristics like charisma, control of the situation and self-esteem are important for the construction of reality and hence for strategic decision-making.

\subsection{Executive experiences and organizational outcomes}

The last twenty-five years have seen a growing number of studies on the relationship between the individual and collective experiences of individuals and the firm's performance. These studies seek to show how these experiences influence values, visions, beliefs and models that affect decision-making, strategic choices and the behavior of individuals. Hambrick \& Mason (1984) seek to show how individuals attempt to recreate patterns and scenarios in their organizations. To understand executives' backgrounds, researchers can predict what will happen in the organization.

Among the variables studied, four stand out with respect to executive experience with organizational outcomes: executive tenure, functional experience, formal education and international experience.

The relationship between executive tenure and organizational outcomes is analyzed from various perspectives. Hambrick and Fukutomi (1991) and Miller (1991) consider tenure as equivalent to the time in the current position. Thomas, Litscheert and Tamaswamy (1991) view tenure as equivalent to time in the organization. Meanwhile, Hambrick, Galetkanycz and Frerickson (1993) see tenure as how long an executive has been in the respective industry. The first part of the studies on the relationship between executive tenure and organizational outcomes has to do with the psychological aspects.

Studies have shown a close relationship between executive tenure and organizational strategies. At the beginning of a mandate, it is more common to identify strategic changes. This initial stage is followed by a period of maturation in which few changes occur, especially in the most important aspects of the organization. Finkelstein and Hambrick (1990) identified a relationship between tenure and what they called strategic persistence.

According to the authors, as the tenure of an executive lengthens, there will be fewer strategic changes and the organizational will adopted a greater strategy of compliance with the industry averages. The relationship between executive tenure and strategic change is moderated by environmental dynamism. The longer an executive's tenure, the greater the emphasis on strategic stability and efficiency rather than product or marketing innovation.

Studies have also shown a relationship between executive tenure and organizational outcomes. This relationship is in the form of an inverted U. The higher the environmental dynamism, the sooner the relationship between the executive tenure and organization outcomes will become negative. Longterm executive tenure is more positive (or less negative), in terms of organizational outcomes, in companies with a strategy of defense rather than one of prospecting.

Functional executive experience is also related to executive perceptions, pattern making and strategic choices. These experiences are related both to the professional and academic background. The interpretation of strategic stimuli and the market considers all the experiences for the final product of the executive decision (Dearborn \& Simon, 1958).

There are several relationships mapped in the book that link executive experience and organizational outcome. These relationships can be used as propositions for future studies in the field.

- Relationship in terms of cultural environment and formal education: The greater the emphasis on general management in the broader cultural environment, the weaker the relationship between the functional scenarios of executives and their interpretation of strategic stimuli. The more formal education in administration executives have, the weaker the relationship between the functional scenarios of executives and their interpretation of strategic stimuli.

- Relationship in terms of strategic stimuli: The more ambiguous and innumerable the strategic stimuli are, the stronger the relationship between the functional scenarios of executives and their interpretation of these stimuli. The shorter the time that executives have to analyze the strategic stimuli, the stronger the relationship between the functional scenarios of executives and their interpretation of these stimuli. The higher the demand for executive work, the stronger the relationship between the 
functional scenarios of executives and their interpretation of strategic stimuli. The greater the length of service in operational areas, the stronger the relationship between the functional scenarios of executives and their interpretation of strategic stimuli.

Executives with background experience in marketing functions, sales or R\&D tend to pursue prospecting strategies, while those with previous experience in manufacturing functions, finance, management or controlling tend to pursue defense strategies. Organizations pursuing prospecting strategies perform well as its top executives have experience in marketing functions, sales or R\&D. Organizations pursuing defense strategies perform well as their top executives have experience in manufacturing functions, finance, management or controlling. Organizations pursuing competitive strategies aligned with the management characteristics of top executives perform better than organizations that do not have this alignment. The effects of the characteristics of top executives on the performance of an organization are greater as these characteristics differ from the profile of executives from competing organizations.

It is evident, according to the authors, that executives make choices based on their scenarios, background, experiences and formal education, basing their interpretation on these custom elements, and consequently making decisions. Organizations thus emerge as a reflection of their top executives, and organizational choices are reflections of the characteristics of their executives. Understanding the executives' scenarios allows the scenarios of organizations to be clarified.

\subsection{Top management teams}

Scholars have focused on researching top management teams for five main reasons. First, because companies have several goals that are often in conflict at the highest level of the organization, where leaders struggle to achieve them. Second, because the process of strategic decision-making considers stages where top management leaders are involved. Third, because the interaction between top management regarding the distribution of forces and possible outcomes of decision-making are of interest to researchers. Fourth, because there is a clear differentiation of top management team roles. Fifth and most importantly is that the study of top management teams and the CEO enables better predictions of organizational outcomes.

Top management teams have three conceptual elements: composition, structure and process. Composition is related to the collective characteristics of teams such as values, knowledge base, personality and experiences. The structure of the teams is defined as the role of members and the relationship between these roles. Process means the nature of the interaction in the team of top management, i.e., as they engage in strategic decision-making. Strategic decisions do not come from nowhere. They originate from social interaction and top management team policy.

The top management team consists of the group of executives with great power to affect the strategic direction of an organization. It is imperative to consider the relative power of each executive in the strategic decision-making process. According to Finkelstein (1992), power comes from structure, prestige, property and specialty.

According to the authors, one of the most studied characteristics among top management teams is demographic heterogeneity, which can be considered a proxy for cognitive heterogeneity, representing inventiveness, problem solving, creativity, openness to change, and willingness to challenge and be challenged. The greater the population heterogeneity within the top management team's cognitive heterogeneity, the lower the degree of socialization and team consensus. The greater the social integration of top management teams, the greater the degree of consensus within the team. The larger the size of the management team, the greater the degree of cognitive heterogeneity. The lower the degree of socialization of the team, the lower the degree of team consensus. The effects of the heterogeneity of the top management on another team's characteristics are stronger when the relative strength of each member is considered in the heterogeneity.

The CEO plays an important role in the interaction of the team's process. If the CEO does not encourage an open debate, is autocratic or does not tolerate dissent, then the top management team may not be relevant to the decision-making process. On the other hand, if the CEO encourages open discussion and the top management become the central component of the formulation and implementation of strategy, then the team will be increasingly empowered. The CEO has the vision of the company and must communicate this vision to its top management team so that decisions reflect this vision. The CEO's charisma has a major impact on the team's performance. Top management teams are subject to the influence of the environment, the organization and characteristics of the CEO. The more diverse the environment, the more the organization needs a differentiated team to monitor this diversity.

The more complex the environment, the greater the heterogeneity of the top management team and the greater the size of the top management team. The complexity of the organizational environment promotes a large difference in the top management team and reduces the opportunity for interacting executives to share resources and operate in a cohesive manner. The more complex the environment, the lesser the interdependence of roles within the top management team. Complexity organization has a direct effect on 
the social integration of teams and consensus. The more complex the environment, the lower the degree of socialization and the lower the degree of consensus in the top management team.

The instability of the environment also influences how organizations are structured and how they operate. Few studies have proved that environmental instability affects the top management teams. The more unstable the environment, the greater the heterogeneity of the top management team and the larger the size of the top management team. It is expected that the consensus of the top management teams is more difficult due to instability as the result of diverse opinions and conflict. The more unstable the environment, the lower is the degree of interdependence of roles within the top management team. The lower the degree of socialization within the top management team, the lower the degree of consensus.

According to the book, strategy and organizational outcomes affect top management teams. Companies with a diverse and interdependent posture have abundant negotiation between the units and must have high levels of collaboration between them. This feature leads to having a team of corporate managers with an excellent degree of relationship, a single corporate vision and a common language.

Companies that have a prospecting strategy must have different teams from those that have a defense strategy. The stability of companies with defense strategies suggests that they face few strategic contingencies and do not require large and differentiated top management teams. On the other hand, companies with a prospecting strategy need to be receptive to change and innovation.

Companies that have defense strategies have a less heterogeneous top management team than companies with a prospecting strategy. They also have fewer members in the top management team, greater social integration among the top management and enjoy greater consensus within the top management team than companies with a prospecting strategy enjoy.

Organizational outcomes can tremendous huge consequences on the top management team. Organizations with abundant resources relative to their demand tend to have several strategic options, while underperforming companies have limited resources. When organizational outcomes are very low or very high, top management teams are larger. TMTs have fewer members when performance is moderate.

Other aspects related to top management teams such as interdependent roles, social integration and consensus are affected by high or low performance. According to the book, the TMT of organizations with abundant resources does not need to worry about managing tradeoffs, and under these conditions, the teams do not need to interact to negotiate resources. On the other hand, management teams with scarce resources need to interact to make better use of what is available.
The role of the CEO is critical to the composition and functioning of top management teams. The CEO can influence his team and the strategic decision process through his charisma and open attitude to work in teams and bring new perspectives to the organization. The greater the dominance of the $\mathrm{CEO}$, the greater his influence on the top management team. Dominant CEOs tend to select top management managers similar to themselves. Another aspect seen in structures with a dominant CEO is a tendency to add people to his staff who can protect his position of dominance. The dominant profile can also reduce the team's level of consensus when defining a strategic position. When the CEO is less dominant, there is a greater exchange of information and decision-making tends to be more consensual within the top management team.

The strategic decision process consists of a series of stages starting with the generation of strategic choices, a review of these alternatives, strategic choice implementation and, finally, an assessment of the choice. Strategy formulation requires an analysis of external threats and opportunities and internal strengths and weaknesses. TMTs are active in this process. Teams with characteristics such as size and heterogeneity generate more strategic alternatives than those without these attributes. The quality of strategic decisions is positively associated with the diversity and size of the TMT and negatively linked to social integration within the TMT.

Strategy implementation involves the mobilization of necessary resources to ensure that strategic initiatives are properly implemented. This process will face resistance from leaders who feel directly affected by the changes and who will work for the project not be successfully implemented. Therefore, it is very important to gain acceptance and commitment from these people to the implementation process of strategic initiatives. The effectiveness of strategic implementation is positively associated with social integration and consensus within the TMT and negatively lined to its size and heterogeneity.

\subsection{Changes at the top: the antecedents of executive turnover and succession}

Changes at the top are motivated by several factors and conditions, ranging from organizational outcomes, conditions of owner-manager relationship, organizational characteristics, environment and the incumbent CEO or predecessor. All these elements, singly or combined, can set the stage for succession (event or process). These elements are also important for understanding the ideal characteristics of a successor, e.g., whether it is important to be similar to the predecessor or comes from within the organization or outside.

There are several drivers of an executive's departure: death, illness, compulsory or early retirement for personal reasons, career repositioning in 
another company, and even dismissal, to name a few. The first (death and illness) account for under 5\% of senior executive departure rates. Retirements and career repositioning have a more significant impact. The study of cases of dismissal emerges as the most interesting under the aegis of the theory because dismissal may occur due to a variety of factors and variables. Often, the real reasons behind an executive's dismissal are not made clear.

When asked why an executive loses his job, the first answer is low organizational outcomes. Poor performance is cause for dismissal. Studies also show poor performance of shares on the stock market and/or profitability measures as the cause of an executive's removal. Performance indicators can thus be linked to the tenure of top executives and the TMT.

With the increasing separation of ownership and control of organizations, studies on the relationship between the CEO's tenure and the property setting/owner's profile gained relevance under the aegis of the Agency Theory. These studies have shown that when an organization has a single owner, profitability is related to the longevity of the CEO in office, while in companies where ownership is divided into shares, the return on stocks is more important. In family businesses, the CEO's relationship with the owners determines his time in office, which is often performance related.

In the Agency Theory, other factors can affect the longevity of the CEO and cause his dismissal. Large organizations have more frequent CEO turnover than small organizations, which are more likely to dismiss their CEO than large organizations. Family organizations are more likely to dismiss a CEO that is not a family member and less likely when they are. The effects of recent performance on the resignation of the CEO will be moderated by his cumulative history throughout his time in office. The greater his prior cumulative performance, the less effect of recent performance shortfalls in terms of his dismissal. Organizations with divisional structure have higher CEO turnover than those that are functionally organized.

CEO succession is also influenced by external factors, such as industry age, growth rates, number of organizations in an industry, conducting IPO, environmental discontinuities and the effects of certain fads.

The succession process can take many forms. The number 2 executive can take over silently, calm as a simple charge of transmission. There may also be a lot of noise. There may be a race for the succession, with several candidates for the post. There may be a real succession crisis without candidates, or a real power struggle. The process can also be impacted by the relationship between the CEO and the Board.

A succession race is more likely than a single change if (1) the company has divisional organization with multiple general management positions that serve as test steps towards CEO; (2) major operating units are of approximately equal size; and (3) more than one of the major operations are relatively high performance.

The more stable the industry and the organization outcomes, the sooner an apparent successor will be selected (via transfer or early succession race). If the environment or strategic position is turbulent, decision makers are more likely to postpone the choice of a new CEO, to be sure of the emerging characteristics required for qualification of leadership.

CEO selection from outside or within the organization enters this context, and adds the role of performance that the organization has shown in the recent past. For example, poor performance and check out tend to be combined variables. Selecting a CEO from outside is a strong sign of change, important in low performance times, for example.

The more stable the environment, the more the successor will resemble the predecessor in terms of time in the company, industry, functional history, business experience and education. The more powerful the predecessor CEO, more the successor will resemble him. The less powerful or vigilant the board, the more the successor CEO will resemble his predecessor. The higher the recent organizational outcomes, the more the successor will resemble his predecessor. A weak recent performance, in contrast, will mean that the successor is more likely to be different from his predecessor.

Specific performance loss types are associated with specific features of the successor. For example: (1) weak growth favors candidates with experience in marketing or sales or with a history of growth in business; (2) low profits, but with satisfactory growth or expansion of market share, favor candidates with experience in operations and control or historical consolidation or rationalization in business; (3) litigation problems or apparent lack of ethics favor candidates with legal experience.

\subsection{Changes at the top: the consequences of executive turnover and succession}

The process of succession of top management executives affects organizational outcomes. There are classic executive succession examples in which organizational outcomes worsened or improved following the entry of the new executive. Building a constructive and supportive relationship with top management is one of the most important factors for the survival of the executive in the early years of his administration. It shows a high rate of executive resignations at the beginning of his succession because they are under pressure to demonstrate its effectiveness and cannot simply take time to build relationships, but need to show concrete actions for improvement.

New executives brought from outside the organization tend to make more strategic changes than those promoted from within. The combination of the entrance of the new executive, the executive team 
aligned with the needs of the business and the need for the executive to demonstrate the effectiveness of his actions will result in strategic actions that reflect the baggage brought by the new executive. Studies show that few executives from outside the organization implemented organizational changes compared to executives promoted internally. One reason for this is that internal executives have more knowledge of the company and can make faster decisions than those who are new and do not have this knowledge. The failure rate is high with external executives because of the high expectations of the Board and TMT in terms of change.

The greater the organization's performance before the successor's arrival, the greater the strategic changes made by the successor. The more the successor differs from the predecessor, the bigger the changes made by the successor. The more different the external successor is in terms of branch of industry, the greater the changes he will make. The correspondence between the executive's background, the amount and types of implemented strategic changes will be higher in the first years of management than at any other time. The higher the correlation between the new executive's mandate, his experience and the amount of strategic changes implemented, the greater the likelihood that the executive will survive the first three years in office. The greater the power of the executive within the top management team, the smaller will be his chance of dismissal in the event of slow organizational performance.

Demographic factors may influence executive turnover. The more heterogeneous the top management team in terms of time in the company, the higher the turnover rate. The greater the age difference between an executive and the larger group of executives, the greater the likelihood of turnover. Demographic similarity helps social integration, aiding communication and harmony in the team. The greater the demographic differences in the top management team, the greater the degree of turnover within the group. The higher the demographic difference of a determined executive within the top management team, the more likely he will be to leave the company. The larger the population difference of a determined executive in relation to the greater executive, the greater the likelihood of the former leaving the organization.

Another context of high turnover is company purchases. The turnover of acquired business executives is double that of normal circumstances. A winning environment shapes acquisitions. If the purchaser of a company is domineering and reveals this in his labor relations, executives of the acquired company will be affected. If these executives feel inferior and dominated by executives from the acquiring company, they tend to leave the organization. Perceptions and behavior of superiority and inferiority are related to company performance.

\subsection{Understanding Board structure, composition,} and vigilance

Studies focus on two important questions: what do boards actually do and how do they operate? Environmental contingencies (such as origins, impositions, institutional forces and organizational conditions) and distribution of power between CEO and Board influence the structure and composition of the Board. These same factors imply that the Board actively monitors and disciplines top executives and is involved in shaping organizational strategy. The aforementioned board activities greatly affect organizational outcomes, as well as succession and executive compensation.

The board size, division of labor and responsibilities of its members, the CEO and the committees are the main points of the Board's structure. As for the composition, factors such as origin and affiliation, demographic scenarios, experience and expertise are the most important points. Understanding the board composition is important to understanding the positions that each member takes, including protecting the interests of those it represents. However, in addition to the origin or representation, demographic characteristics such as gender, age, race, management experience, industry experience and tenure can reveal the intricacies of the organization and its choices. Ownership of company shares by board members is also a relevant factor in its composition.

The lower the organization's outcomes, the greater the likelihood that a director will be removed. The greater the number and prestige of other directors over one director, the greater the likelihood that this director will be removed in underperforming organizations.

These proposals demonstrate an implication of low performance for external executives of organizations, those who are not its main shareholders, owners or family members, if applicable. The performance and reputation of the Board, and consequently its composition have a strong relationship.

The greater the need for effective monitoring, the greater the incidence of board characteristics that strengthen its independence. The higher the relative power given by the Board to the CEO, the stronger the relationship between the need for effective monitoring and board features that strengthen their independence.

Resulting from the study of these propositions, five predictions are listed: underperforming CEOs are more susceptible to repositioning than those with high performance; the sensitivity of CEO turnover is moderated by board independence; the possibility of outside directors joining the board grows with weaker performance; board independence decreases as the CEO tenure increases; performance measures are better predictors of CEO turnover than market measures.

The greater the power of the CEO, the greater his involvement in selecting new directors (board 
members) and the higher the proportion of staff officers or those professionally connected to it. As each board member effectively monitors and disciplines the top executives, the power of the director or the front board grows concerning the CEO. However, in practice, this is a more complex task, and shows why some directors can be more effective than others in the primary task of ensuring that top executives play consistent roles in accordance with the interests of shareholders.

The higher the relative power of the board over the top management team, the greater its vigilance. The higher the proportion of independent directors on the board or the higher the percentage of stock ownership of outside directors on the board, the greater the board's supervision.

The dual roles of CEO, when head of the board, may restrict vigilance. Studies show two relationships between CEO and board: competition and cooperation. This relationship undoubtedly is the major organizational challenge, interfering with choices, strategies, and organization outcomes.

\subsection{The consequences of board involvement and vigilance}

The Board of Directors is very important for corporate governance and thus it is expected to be vigilant of the actions of the TMT for which the shareholders are responsible. They also have an important role to advise top management to be involved in the company strategy formation. Studies show that the role of the board of directors in strategy formulation is consulting and assessment to start the process of strategic training. Outside executives rarely initiate the strategic process and when this happens, it is probably because the internal executives have little experience in the field. The larger the Board, the less involved it is in strategic decisions.

The demographics of the board can influence strategic decisions. The diversity of the board may be associated with low involvement in strategy. The greater the diversity of experiences, the more involved the Board will be in the strategic decision making process. The involvement of the board in strategic decisions varies according to the process stages. The Board will be involved in the following stages of strategic decision: evaluation of strategic alternatives, evaluation of strategic outcomes, selection strategies, generating strategic alternatives and implementing strategies.

Boards of Directors can be more involved in strategic issues in start-ups and small businesses that need to create policies and have clear rules for decision making within the organization. The older the organization, the less involved the Board will be in strategic decisions. Board involvement to generate, evaluate and select strategies is more negatively associated with the age of the organization than involvement of the board to implement and evaluate the strategy's outcomes. The larger the organization, the less involved the Board will be in strategic decisions. Board involvement to generate, evaluate and select strategies is more negatively associated with the organization size than board involvement to implement and evaluate the strategy's outcomes. The larger the acquisitions, sales and joint ventures, the more involved the Board will be in all stages of the process of strategic decision-making.

The involvement of the Board in CEO turnover can also be gauged. Boards with high power tend to select the new CEO with the board's profile rather than that of the departing CEO. The selection of a new CEO increases the involvement of the Board in all stages of the strategic decision-making process. CEO tenure decreases board involvement at all stages of the strategic decision making process.

Institutional forces such as executive prestige can influence corporate governance, being a key antecedent to the selection and turnover of board members. Executive prestige can give board members a great opportunity to participate in the strategy process. The higher the prestige of the board, the greater its involvement in all stages of the strategic decisionmaking process.

Another aspect that can influence the involvement of directors in the process of training and decision strategy are the bonds of friendship between them. When the bonds of friendship between CEO and board members are strong, the Board provides more warnings and suggestions to the CEO, resulting in increased organizational outcomes. The higher the ties of friendship between the Board members, TMT and $\mathrm{CEO}$, the greater the involvement in all stages of strategic decision-making.

Boards with strength and power are more vigilant than weaker boards and thus should be more active in shaping strategy. The greater the strength of the board, the greater its involvement in all stages of strategic decision-making, and the stronger the relationship between critical contingencies and board involvement in strategic decisions.

Although the Board does not always use its implicit power to influence organizational outcomes, such as strategy, it is influential in a wide range of outcomes related to strategic leadership. Through advices to the CEO, the Board may indirectly affect company strategy. Business performance is related to the Board's composition. Studies show that the more diverse the board composition, the lower the likelihood of board members speaking at board meetings, even if there are concerns over company strategy. Board members in a demographic minority tend not to speak at meetings unless they are friends with other directors.

Other findings of studies show that external Board members tend to prioritize financial controls and the reduction of expenditure on R\&D. Other studies show that internal board members prefer a portfolio of low-risk projects, while external members prefer a high-risk portfolio. High-risk projects are related 
directly to $\mathrm{R} \& \mathrm{D}$ expenditure, and this contradicts the findings of the previous study.

Empirical evidence suggests that external board members are more influenced by the strategy of their home businesses than the strategy of other boards on which they are members.

The functional background and time that members bring influence the definition of strategy. The allocation of resources to a company between different functions is positively associated with how these functions are related to the background of the board members. The association between demographic characteristics of the Board and organizational outcomes is moderated by the relative distribution of power between the board members.

The idea that board members assume a role more closely related to monitors of the organization than being involved in decision-making strategy is widely accepted. Studies show that the structure and composition of board members are less in the way of attributes and more as potential determinants.

\subsection{The determinants of executive compensation}

In a growing number of organizations with separation of ownership and management, the issue of financial compensation or remuneration of executives emerges. Variables such as company size and profitability are determinants in this relationship. Only in recent studies have other variables such as risk and power been considered.

Most of the time, economic explanations have prevailed in an attempt to explain the compensation of executives. Thus, variables such as sales and profits were predominant. The larger the firm, the greater the compensation thesis. For the executive, it becomes a more manageable equation than profit itself. Larger companies can afford to pay more, and provide other benefits beyond direct compensation. Thus, the focus on expanding the size of the organization, in a way, means focusing on increasing the compensation. Thus, larger firms pay more and a CEO earns more if he increases the size of an organization.

Neoclassical economists, in turn, have shown show that profitability better explains the remuneration of the executive, and not only their remuneration but also its influence and rewards, because their interests are aligned with those of shareholders. This shows the relationship between compensation and performance. Some variables can be included in the study of the relationship between performance (of the organization) and remuneration (of the CEO).

In addition to economic theories, there are also social explanations for executive compensation, such as the relationship between increased knowledge of the compensation paid to executives by stakeholders, and the existence of paid consultants to support decisions. New laws, regulations or agencies designed to expand disclosure of executive compensation to shareholders in a country increases as the magnitude of remuneration to executives in that country decreases.

As growing knowledge of remuneration becomes public, there is a tendency or isomorphic pressure over standardizing compensation in an industry, as comparison is possible and real. Remuneration has become a component of the social context, where legitimacy matters. Benefits and incentives, whether financial or non-financial, are also influenced by social context. The higher the level of managerial discretion in an industry, the greater the variation in CEO compensation in this industry. The greater the isomorphic pressures in an industry, the lower the variation in CEO compensation in this industry.

Financial incentives are negatively associated with non-financial incentives. Social capital will be positively associated with executive compensation as environmental conditions or strategic context require such capital. Capital aimed at institutional or governmental actors will be associated with executive compensation in the more highly regulated organizations than in others.

In addition to the economic and social arguments to explain the phenomenon of executive remuneration, there are also political arguments. Compensation due to power, for example, means remuneration is indicative of power. This power relationship is always based on the relative power of the individual versus group power (the Board, most of the time).

Executive remuneration is not determined only by objective factors and is not only related to organizational outcomes. Social and political factors strongly affect remuneration and highlight a complex variable in this relationship: the individual and his motivations. The relationship between pay and performance, in addition to being stable, is directed by contingency, depending on factors like the effectiveness of the Board, the preferences of the CEO, types of compensation, the nature and managerial discretion available, risk and context.

\subsection{Executive compensation: consequences and distributions}

The payment, which an executive receives for his work, can have many consequences for himself, the top management team, organization and its stakeholders. Payment may affect company performance in the strategic decision-making process, managerial motivation, turnover and behavior. The basic premise of agency theory is that contracts are made for executives to maximize organizational outcomes. Studies show that long-term compensation such as bonuses or policy actions (stock option) promote good acceptance and ensure a long tenure of the CEO. Compensation is related to strategic changes, increased investment and organizational profitability, 
but this cannot be considered a general empirical observation.

Donaldson and Lorsch (1993) interviewed top executives of twelve large companies and one of their main conclusions was that, unlike economic theory, executives were not motivated only by financial incentives. Executives demonstrated that they were motivated by being better than similar executives in other companies.

The shorter the CEO tenure, the more positive the relationship between financial incentives and strategic change. The relationship between financial incentives and strategic changes is more positive in more discriminating contexts than in lesser ones. The higher the competitive intensity in a company, the more positive the relationship between financial incentives and strategic change will be.

Studies have assessed the association of executive compensation, strategy and the diversification process (organic growth or growth through acquisitions). Executive compensation was positively associated with the performance of companies with an organic growth profile and growth through acquisitions. Organizational outcomes are partly a function of the degree of compensation strategy and corporate strategy.

The agency theory predicts that risk taking behavior changes according to the type of problem. While the agency theory considers risk aversion as a motivating force for decision-making, behavioral approaches cited aversion to loss as a motivating force. There is empirical evidence that executives take on greater risk to avoid a loss than to generate a gain.

The agency theory suggests that the more the executive gains in terms of salary, the more risk averse he will become because he will have a great deal to lose if the company has bad outcomes. The higher the executive compensation for similar groups, the lower the turnover will be. The higher the level of compensation of the executive, the higher the level of the political behavior of executives. The adoption of executive compensation for performance increases the degree of political behavior on the part of executives.

Why do some executives earn more than others in the same company? The basic premise is that executives are motivated to perform their work and work hard because they wish to achieve their goals to reach new positions and are promoted and consequently gain higher rewards for their efforts. CEO is the highest position that can be achieved by a top executive in an organization. The senior executive compensation structure is defined to have increases as the executive rises in the organization. Studies show that there is a wide gap in pay between the CEO and the second highest rank. The differences in remuneration over the hierarchical levels can define a need to demarcate the structure of the organization. The size of the gap between CEO compensation and the level immediately below it can be an indicator of a CEO autocracy.
The competitive model of compensation tends to emphasize the need for external incentives and underestimates the reasons why executives are motivated. CEOs are highly motivated by the challenging nature of their work, its intrinsic value, the need for security, power and the need to build a reputation of success in the labor market. Other studies show that wage gaps are motivators for executives in diverse companies. However, they are not motivators for companies focused on a specific field.

Difference in pay is a critical element in compensation for an executive to influence his behavior within the group and can be a differentiator when comparing the group level. The relative power of senior executive defines the size of the difference in pay between them. Heterogeneity of TMTs in terms of time and functional background is positively related to the differences in pay between senior managers and other similar positions.

The greater the gap in pay between the CEO and the rest of the TMT, the greater the team's fragmentation will be and the lower the integration of executive team behavior. However, the greater the dispersion in compensation of the TMT, the greater its fragmentation and the lower the behavioral integration of the executive team. The ratio gap between CEO compensation and the rest of the team and the company's performance is mediated by fragmentation and behavioral team integration.

There is a large group of potential consequences of executive compensation (functional, non-functional, intended and unintended). The propositions listed above reveal conflicts between the perspectives due to different assumptions, but offers a great opportunity for future academic research.

\section{IMPLICATIONS}

A small group of people at the top of an organization dramatically affects its outcomes. Top management works in a complex and ambiguous world. An important part of strategic decisions stem from executive experiences, preferences and personality. Executives have their own values and behavior.

Understanding the overview of the top management world will allow scholars to understand what happen inside organizations. Other scholars analyze how the corporate environment influences executives' characteristics and behaviors, something akin to an alignment between the executive and the environment in which he works.

Top Management Teams (TMT) are groups of executives with sufficient power to affect the strategic direction of an organization. Changes at the top occur due to several factors and conditions such as company performance, relationship with the owner, organizational profile and company environment. All these elements, in isolation or combined, can create a 
succession scenario within the organization. The succession process of top executives can affect company results. There are classic examples of executive succession where company results improved or became worse following the arrival of the new executive. Building a constructive relationship with the TMT is one of the key factor in sustaining an executive in his first years of activity.

What board members do and how they act are the main questions that scholars are striving to answer. Environmental contingencies, such as institutional forces, organizational conditions and roadblocks, stem from several parts from the organization, influence the structure and composition of the Board. These factors influence board activities regarding monitoring and controlling the top executives as well participating in the strategic decision-making process. Board activities influence company outcomes and the executive payroll. Corporate governance is important for board members because the Board is expected to be vigilant regarding executive actions. The Board plays an important role in coaching the top management about strategy the decision-making process.

On the order hand, it is important to highlight that the top management team is an important group in the organization, but there are other executives who also play important part. The senior and/or medium managers represent a significant part of the decisions that influence and affect the outcomes. Their decisions are more related to the daily decisions and has a greater impact on the process details, despite influencing the outcomes of the organization and firm. The book does not take this group into consideration; nor does it consider this kind of decision, centering the theory on the upper echelons. All the implications of the theory are focused on the top management team, and there are many ways for scholars to develop new ideas involving other levels of management.

\section{FINAL SUMMARY}

The book "Strategic Leadership" summarizes what is known about the subject and shows other directions for further research. The book serves as a reference for researchers who want to understand the phenomenon of strategic leadership. The content of the work summarizes what is known about strategic leadership and offers considerable foundations for executives and researchers in the fields of business, compensation, performance and behavior of the Board of Directors. There is space for the development of new studies on the other leaders in organizations. It is also possible to conduct research to confirm the findings in other kinds of market, such as emerging countries.

\section{REFERENCES}

Abrahamson, E., \& Hambrick, D. C. (1997). Attentional homegeneity in industries: The effect of discretion. Journal of Organizational Behavior, pp. 513-532.

Child, J. (1972). Organization structure, environment and performance: The role of strategic choice.

Dearborn, D. W., \& Simon, H. A. (1958). Selective perception: A note on the departmental affiliations of executives. Socimetry, pp. 144-150.

Donaldson, G. A., \& W.Lorsch, J. (1983). Decision making at the top. New York: Basic Books.

Fayol, H. (1949). General and industrial management. London: Pitman.

Filkenstein, S. (1992). Power in top management teams: Dimensions, measurement and validation. Academy of Management Journal, pp. 505-538.

Filkenstein, S., \& Hambrick, D. C. (1990). Top management team tenure and organizational outcomes: The moderating role of managerial discretion. Administrative Science Quarterly, pp. 484-503.

Filkenstein, S., \& Peteraf, M. A. (2007). Managerial activities: A missing link in managerial discretion theory. Strategic Organization, pp. 237-248.

Filkenstein, S., Hambrick, D. C., \& Cannella, A. A. (2009). Strategic Leadership - Theory and Research on Executives, Top Management and Boards. New York: Oxford.

Hambrick, D. C., \& G.Brandon. (1988). Executive values. In the executive effect: Concepts and methods for studying top managers. JAI Press, pp. 3-34.

Hambrick, D. C., \& GregoryD.S.Fukutomi. (1991). The season of a CEO's tenure. Academy of management Review, pp. 719-742.

Hambrick, D. C., \& Mason, O. (1984). Upper echelons: The organization as a reflection of its top managers. Academy of Management Review, pp. 193-206.

Miller, D. (1991). Stale in the saddle: CEO tenure and the match between organization and evironment. Management Science, pp. 34-52.

Mintzberg, H. (1973). The nature of managerial work. New York: Harper \& Row. 
Implications of Theory and Research on Strategic Leadership: A Critical Review

Rotter, J. B. (1966). generalized expectancies for Psychological Monographs. internal versus external control of reinforcement. 